\title{
Congenital heart disease-associated liver disease: a narrative review
}

\author{
Florian P. Reiter ${ }^{1 \#}$, Nino J. Hadjamu ${ }^{2 \#}$, Nicole Nagdyman ${ }^{3}$, Reinhart Zachoval $^{4}$, Julia Mayerle ${ }^{1}$, \\ Enrico N. De Toni ${ }^{1}$, Harald Kaemmerer ${ }^{3}$, Gerald Denk ${ }^{1,4}$
}

${ }^{1}$ Department of Medicine II, University Hospital, LMU Munich, Munich, Germany; ${ }^{2}$ Department of Cardiology and Vascular Medicine, West German Heart and Vascular Center, University Hospital Essen, Essen, Germany; ${ }^{3}$ Department of Congenital Heart Disease and Pediatric Cardiology, German Heart Center Munich, Technical University Munich, Munich, Germany; ${ }^{4}$ Transplantation Center Munich, University Hospital, LMU Munich, Munich, Germany

Contributions: (I) Conception and design: FP Reiter, NJ Hadjamu, H Kaemmerer, G Denk; (II) Administrative support: None; (III) Provision of study materials or patients: None; (IV) Collection and assembly of data: None; (V) Data analysis and interpretation: FP Reiter, NJ Hadjamu, N Nagdyman, R Zachoval, J Mayerle, EN De Toni, H Kaemmerer, G Denk; (VI) Manuscript writing: All authors; (VII) Final approval of manuscript: All authors.

\#These authors contributed equally to this work.

Correspondence to: Florian P. Reiter, MD. Department of Medicine II, University Hospital, LMU Munich, Marchioninistr. 15, D-81377 Munich, Germany. Email: Florian.Reiter@med.uni-muenchen.de.

\begin{abstract}
Congenital heart diseases (CHD) can be associated with liver dysfunction. The cause for liver impairment can result out of a wide spectrum of different causes, including liver congestion, hypoxemia or low cardiac output. Fortunately, most CHD show a good long-term outcome from a cardiac perspective, but great attention should be paid on non-cardiac health problems that develop frequently in patients suffering from CHD. The treatment of liver dysfunction in CHD requires a close multidisciplinary management in a vulnerable patient collective. Unfortunately, structured recommendations on the management of liver dysfunction in patients with CHD are scarce. The objective of this review is to provide insights on the pathophysiology and etiologies of liver dysfunction as one of the most relevant non-cardiac problems related to CHD. Furthermore, we advise here on the management of liver disease in CHD with special attention on assessment of liver dysfunction, management of portal hypertension as well as on surveillance and management of hepatocellular carcinoma (HCC). A multidisciplinary perspective may help to optimize morbidity and mortality in the long-term course in these patients. However, as evidence is low in many aspects, we encourage the scientific community to perform prospective studies to gain more insights in the treatment of liver dysfunction in patients with CHD.
\end{abstract}

Keywords: Congenital heart disease (CHD); liver disease; liver fibrosis

Submitted Jul 10, 2020. Accepted for publication Oct 15, 2020.

doi: $10.21037 / \mathrm{cdt}-20-595$

View this article at: http://dx.doi.org/10.21037/cdt-20-595

\section{Introduction}

Survival of adult patients with congenital heart diseases (CHD) has increased profoundly over the past decades $(1,2)$. This is not only related to improved surgical or interventional techniques but also to a stringent cardiological surveillance in the medical follow up. Despite the achievements in the treatment of patients with CHD new potentially underestimated non-cardiac health problems related to CHD have become apparent as management of cardiac problems has been optimized over the past decades (3-6). Liver dysfunction is one of the major non-cardiac complications and was observed in $6 \%$ of deceased patients suffering from CHD as assessed by an analysis of the German National Register for CHD (7). E.g., in patients younger than 25 years of age cirrhosis 
occurs 11 to 15 years after Fontan operation (8). Therefore, surveillance of non-cardiac complications especially of liver dysfunction is recommended $(1,9,10)$.

From pathophysiological aspects, hemodynamic alterations can cause liver congestion as a result out of an increased venous pressure, a phenomenon that can lead to cardiac fibrosis or cirrhosis. However, venous congestion is not the only pathophysiological mechanism for the development of liver dysfunction in CHD. In this review we provide insights in the complex pathophysiology of liver diseases associated with CHD and advise on their management from a multidisciplinary perspective. We present the following article in accordance with the NARRATIVE REVIEW reporting checklist (available at http://dx.doi.org/cdt-20-595).

\section{Methods}

As sources for this review a structured MEDLINE search beginning with 1951 until September 2020 was performed. In the context of the little body of evidence, recommendations and perspectives described here also raised from discussions with experts in this field. Finally, personal experience with treatment of patients with CHD from cardiologist and hepatologist perspectives were implemented in this review. Figures 1-3 were created using Adobe Illustrator CC 2019 (CA, USA).

\section{Pathophysiological aspects of liver dysfunction in patients with CHD}

Here we focus on the pathophysiology of liver dysfunction directly related to hemodynamics in CHD. Syndromes that are not only accompanied by liver dysfunction but also with $\mathrm{CHD}$, as it is the case with Alagille syndrome, are outside the scope of this overview. Pathophysiological alterations of liver physiology in CHD are often related to hemodynamic derangements, either resulting from backward failure of the subpulmonary ventricle (venous congestion), from forward failure of the systemic ventricle, or from hypoxemia in cyanotic CHD.

Liver congestion from backward failure of the heart is a frequent phenomenon that can result in the development of cardiac fibrosis and cirrhosis. In order to illustrate the disease mechanism of venous congestion we want to highlight the unique physiological blood supply of the liver. The liver is supplied by the two vessel systems of the hepatic artery and of the portal vein, in which about
$70 \%$ of blood is supplied by the latter (1). Both the hepatic artery and the portal vein system enter the liver acinus from the portal triads (Figure 1). Thereby, the blood enters the capillary system of the liver sinusoids and flows towards the central vein, where the blood is collected and drained into the inferior caval vein. The knowledge of this certain kind of blood supply is essential for understanding the pathophysiology of hemodynamic alterations in CHD. Thus, hepatocytes that are located close to the portal triad are supplied by oxygen- and nutrient-rich blood. The content of oxygen and nutrients decreases by flowing towards the central vein. In respect of these differences there are defined metabolic zones of the liver acinus. Zone I covers the oxygen and nutrient rich periportal zone, while the pericentral zone III, that is connected by a transition zone II to the periportal zone I, has only access to less oxygenated and nutrient rich blood (Figure 1). This situation explains that hemodynamic alterations in CHD caused by venous congestion, by ischemia or by hypoxia affect initially the metabolic most vulnerable zone III $(1,12)$. Therefore it is not unexpected that typical histopathological signs of venous congestion such as sinusoidal dilation, hemorrhagic necrosis and fibrosis occur predominantly in the pericentral zone III (13). This phenomenon causes the distinctive pattern of fibrosis found in liver congestion, which bridges the fibrosis between the central veins (Figure 2) $(14,15)$.

But not only venous congestion itself is responsible for hemodynamic related liver dysfunction in CHD, as oxygen supply can be affected by multiple factors in CHD such as low cardiac output, cyanosis or impaired oxygenation because of lung problems related to CHD. Impaired lung function is observed frequently as non-cardiac problem in CHD $(1,16)$. The impaired oxygen supply becomes particularly relevant when sinusoidal pressure is already elevated due to venous congestion. This in turn reduces portal inflow and makes the liver more susceptible to ischemic alterations due to a reduced flow of the hepatic artery such as in ischemic hepatitis (17). Chronic hepatic ischemia is a known factor for the development of liver fibrosis (13). Thereby, hemodynamic pathophysiology of CHD related liver disease should be seen in the context of both forward and backward cardiac failure.

Portal hypertension is a typical feature of end stage liver disease leading to its various complications. It is a sequel of elevated liver stiffness due to pathological alterations of the liver tissue in chronic liver diseases (18). In addition to patients with primary liver diseases, who 


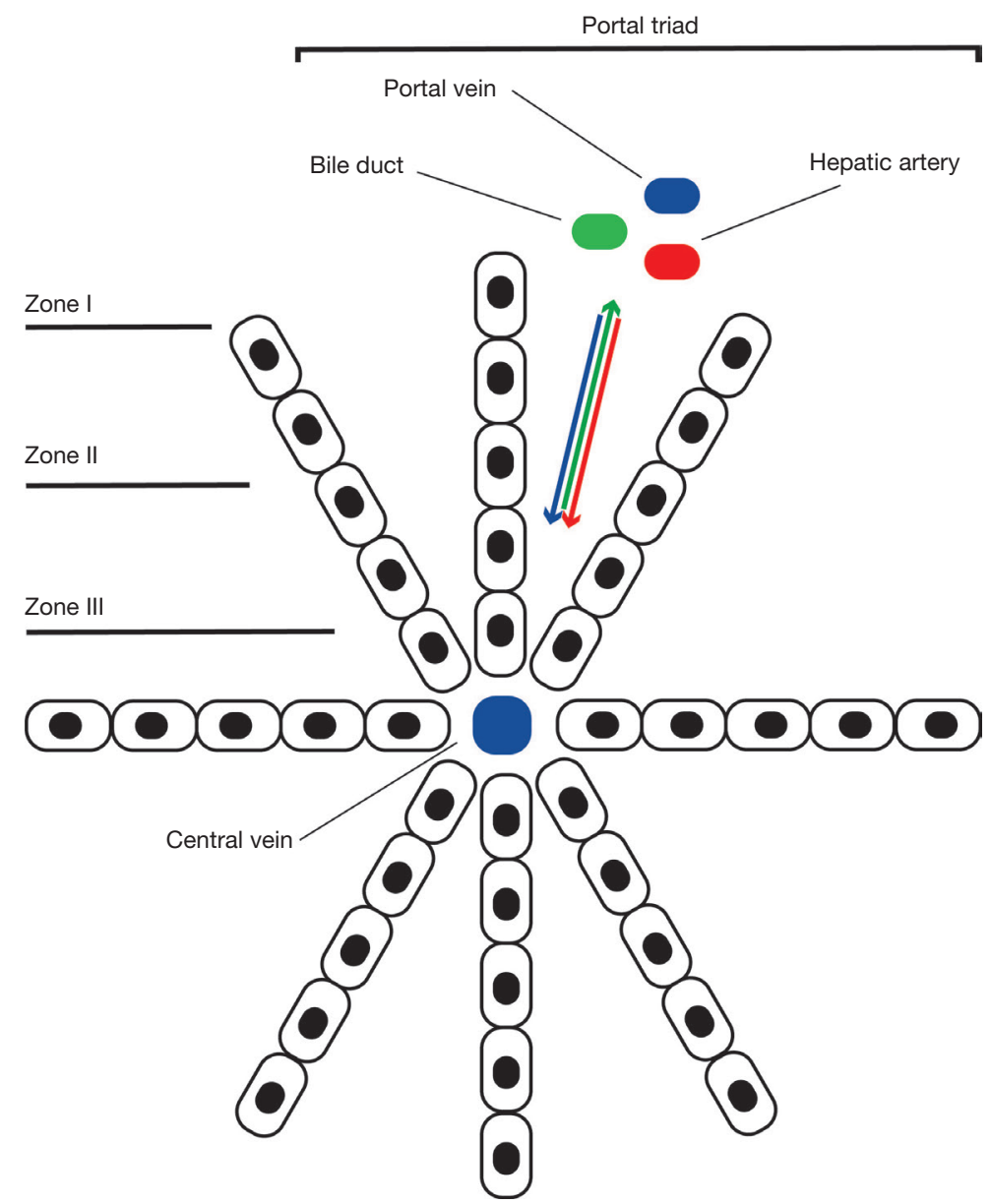

Figure 1 Architecture of the liver acinus and its metabolic zones. The figure illustrates a liver acinus schematically. The unique blood supply of the liver is the essential basis for understanding pathophysiology of liver diseases in CHD. The blood supply enters the liver by the hepatic artery and the portal venous system. Thereby, the blood passes the capillary sinusoidal system of the liver lobules and enters the central vein, which in turn drains the blood to the inferior caval vein. There are three defined metabolic zones in respect to the mentioned blood supply. The pericentral zone III is thereby highly susceptible to hemodynamic alterations not only due to the fact that venous congestion distresses the central vein first but also because ischemic or hypoxic alterations predominantly affect this region as distance to oxygen and nutrient rich blood supply shows the longest distance in zone III. It is plausible when typical changes of cardiac hepatopathy such as sinusoidal dilatation, hemorrhagic necrosis and fibrosis occur predominantly in the pericentral zone III (Figure created by Florian P. Reiter).

suffer from intrahepatic portal hypertension, posthepatic portal hypertension is an important pathomechanism in CHD (18). Prehepatic portal hypertension, as it occurs in non-cirrhotic patients with portal vein thrombosis due to different causes of hypercoagulopathy or other non-hepatic reasons, is not a relevant issue in patients with CHD. The common approach to identify portal hypertension, is to look for its clinical signs such as ascites, Caput Medusae, an enlarged spleen in ultrasound, laboratory signs of hypersplenism such as thrombocytopenia or occurrence of varices in gastroscopy (18). Elastography of the liver, a well established technique in many liver diseases, may be a useful tool to identify patients with CHD at risk for portal hypertension (19). From our point of view, direct invasive determination of the portal pressure should be reserved for very selected cases and not be taken as a standard procedure.

However, liver diseases in CHD do not only occur in the context of hemodynamic alterations. This is also related to the positive fact that survival of these patients increased profoundly over the past decades and fortunately there is a pleasant proportion of patients with CHD older than 65 years of age $(2,20,21)$. This implies several aspects. A 


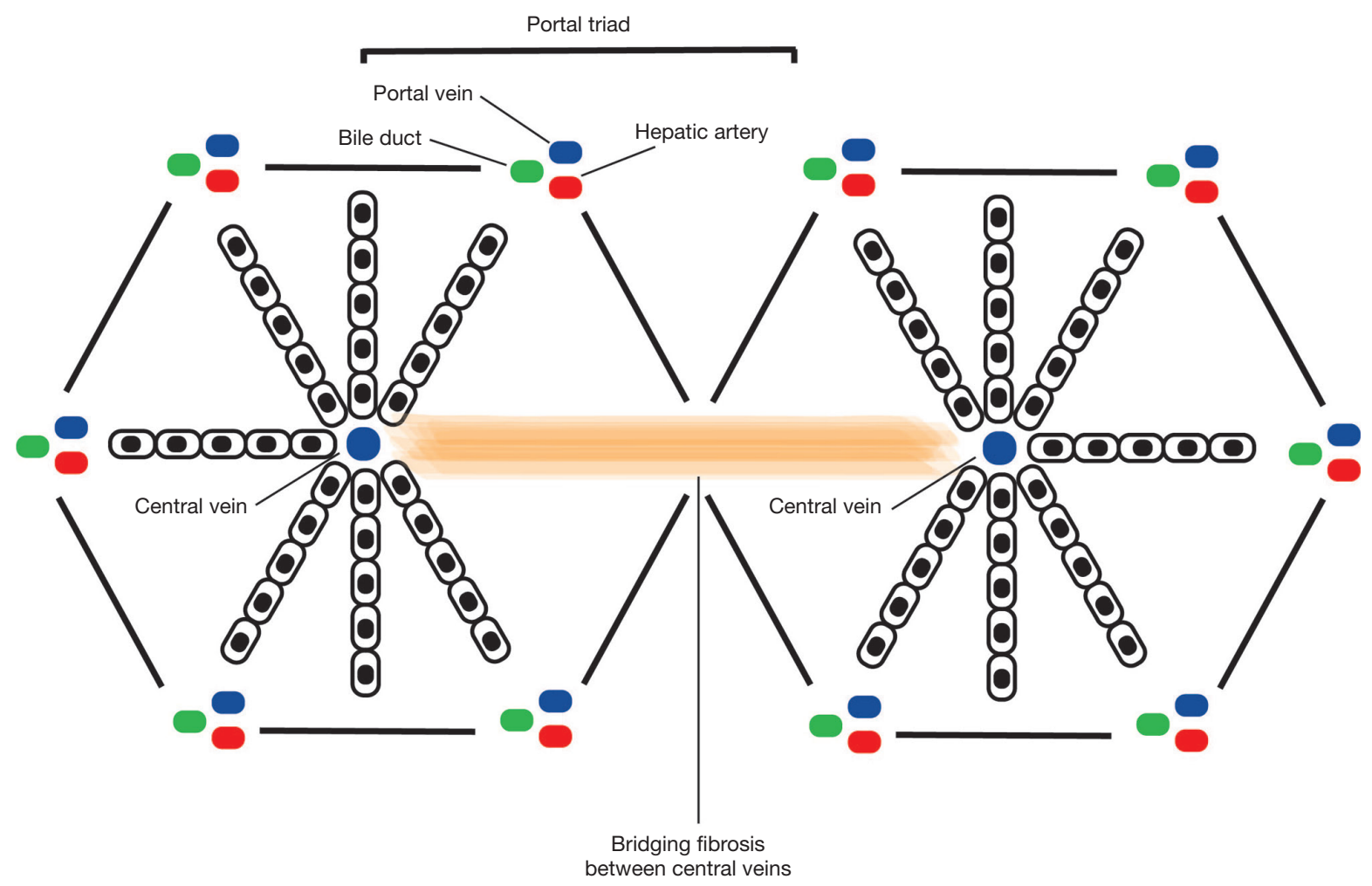

Figure 2 Fibrosis pattern in liver congestion. The figure illustrates schematically the typical pattern of fibrosis between two central veins that can be observed in liver fibrosis related to liver congestion (Figure created by Florian P. Reiter).

relevant number of patients underwent surgery at a time when screening of blood-borne viruses such as hepatitis B and hepatitis $\mathrm{C}$ virus was not available with an increased risk of acquiring chronic viral hepatitis. In this context chronic hepatitis $\mathrm{C}$ was described in around $5 \%$ of patients who underwent surgery for CHB before $1992(22,23)$.

Non-alcoholic fatty liver disease (NAFLD) is a rising problem with an estimated prevalence of $25 \%$ (24). These high numbers were validated in a study by Zhang et al. in patients with CHD with NAFLD in about $36 \%$ of patients with CHD (25). This study indicates that a relevant number of patients with CHD is affected by NAFLD, reflecting this entity as an important cause for liver dysfunction in these patients. Therefore, NAFLD should be considered in the clinical assessment of liver dysfunction in patients with CHD.

Finally, the hepatological work up of patients with CHD should include a careful medication history as well as screening for autonomous liver diseases such as alcoholic, cholestatic or autoimmune liver diseases that may occur independently of hepatic problems related to CHD over a patient's lifetime.

\section{Types of CHD and liver diseases}

Liver changes in the sense of liver congestion, liver fibrosis or liver cirrhosis often occur in the course of serious heart disease and can have a considerable negative impact on the quality of life, morbidity and prognosis of the affected patients. In acquired heart disease, this is usually caused by right heart failure or right heart strain in tricuspid valve disease, cor pulmonale, pulmonary hypertension of any cause or constrictive pericarditis.

Hepatic damage in the context of CHD has been recognized more recently as a relevant problem. Pathophysiologically, liver changes occur in a wide variety of CHDs, and the mechanisms are different:

- Liver changes and hepatic vein congestion may occur if venous blood flow from the inferior vena cava or the hepatic veins to the subpulmonary ventricle or pulmonary circulation is obstructed. This would be typical for baffle stenoses after atrial switch operation (according to Mustard or Senning) in complete transposition of the great arteries or for univentricular hearts after (modified) Fontan- 
Operation.

* Liver vein congestion is also found in CHD with all forms of inborn or secondarily acquired tricuspid valve abnormalities. This concerns in particular tricuspid valve insufficiency, tricuspid valve stenosis, (decompensated) pulmonary valve stenosis or insufficiency, atrial septal defects, Ebstein's anomaly, Fallot's tetralogy with pulmonary regurgitation or with restrictive physiology after reparative surgery as well as all forms of cor pulmonale in pulmonary hypertension of various etiologies. A right ventricular backward failure causes an increase in central venous pressure and thus a passive liver congestion.

* In cyanotic forms of CHD, the resulting hypoxaemia and cyanosis is another important factor leading to liver damage. This concerns on the one hand the uncorrected, primarily cyanotic heart defects, which include above all Fallot's tetralogy, complete transposition of the great arteries, tricuspid atresia, truncus arteriosus communis, total pulmonary venous return and pulmonary atresia with ventricular septal defect or with intact ventricular septum. In addition, there are secondary cyanotic CHD in which an acyanotic left-right shunt existed at first and in which a shunt inversion to a right-left shunt occurred in the course of a resulting pulmonary vascular disease (Eisenmenger syndrome). Depending on the extent of hypoxaemia, necrosis of hepatocytes results with consecutive decrease of liver performance and alteration of liver structure.

* A reduced cardiac output in the sense of a forward failure of the right or left ventricle can cause a decreased arterial blood supply of many organs, including the liver. In addition, severe left heart failure may progress into backward failure and consecutive right failure resulting in liver impairment. This is not uncommon in congenital anomalies of the left heart, which include in particular the congenital forms of mitral valve stenosis and insufficiency, aortic valve stenosis and insufficiency, subvalvular or supravalvular aortic stenosis, aortic coarctation, and hypoplastic left heart syndrome. Such a constellation can of course also occur in the long-term course of all other decompensated CHDs.

* A comparable constellation may occur if a morphologic right systemic ventricle fails.

* Finally, also liver alterations from hepatitis or medical treatment has to be considered in adults with CHD.

In the following, three important CHDs, where the long-term course is often complicated by liver damage, will be discussed in more detail.

\section{Liver changes after atrial switch operation in complete transposition of the great arteries}

After atrial redirection in transposition of the great arteries, the morphologically right ventricle becomes the system ventricle (Figure 3) (11), which cannot withstand its load in the long term. In many cases a dysfunction develops with signs of forward failure, in some cases also a backward failure with congestion of the lungs. Only at a late stage a failure of the subpulmonary, morphologically left ventricle may occur consecutively. Clinically, the latter could cause the clinical picture of a "classical" right heart strain with congestion of the liver, which is, however, only rarely seen.

Liver congestion after atrial switch operation is much more likely seen in the context of a stenosis of the inferior systemic venous baffle (Figure 3). Depending on the observer, the surgeon and the time period in which the surgical intervention was performed, the frequency of such obstruction is $5-10(-40) \%(19,26-28)$. Preferably, patients are affected who were operated in the early stages of atrial redirection surgery or in their first year of life. In such system venous obstructions are typically found at the venoatrial junction or within the corresponding atrium due to fibrosis, re-endothelialization and shrinking processes $(26,28)$. Furthermore, associations with the localization of the sutures, the extent of the atrial septal excision as well as with patch size, shape and the baffle material used are suspected (29). Caval obstructions often develop within the first postoperative weeks and months; later less frequently, as the remaining muscular atrial tissue grows with the patient $(27,30)$. Obstructions may be complete or incomplete, isolated or associated with a pulmonary venous obstruction. Clinically detectable obstructions of the inferior vena cava, sometimes associated with ascites, edema of the lower limbs, hepatomegaly or protein-losing enteropathy, have been seen in up to $30-50 \%$ of cases in previous years. Recently, Nagdyman et al. described in $71 \%$ of patients, who had undergone atrial switch operation, signs of liver fibrosis or even cirrhosis when measured with transient elastography (TE) and acoustic radiation force impulse imaging (ARFI) $(19,31-34)$. It is not uncommon for such an obstruction to remain undetected unless it is specifically looked for using 


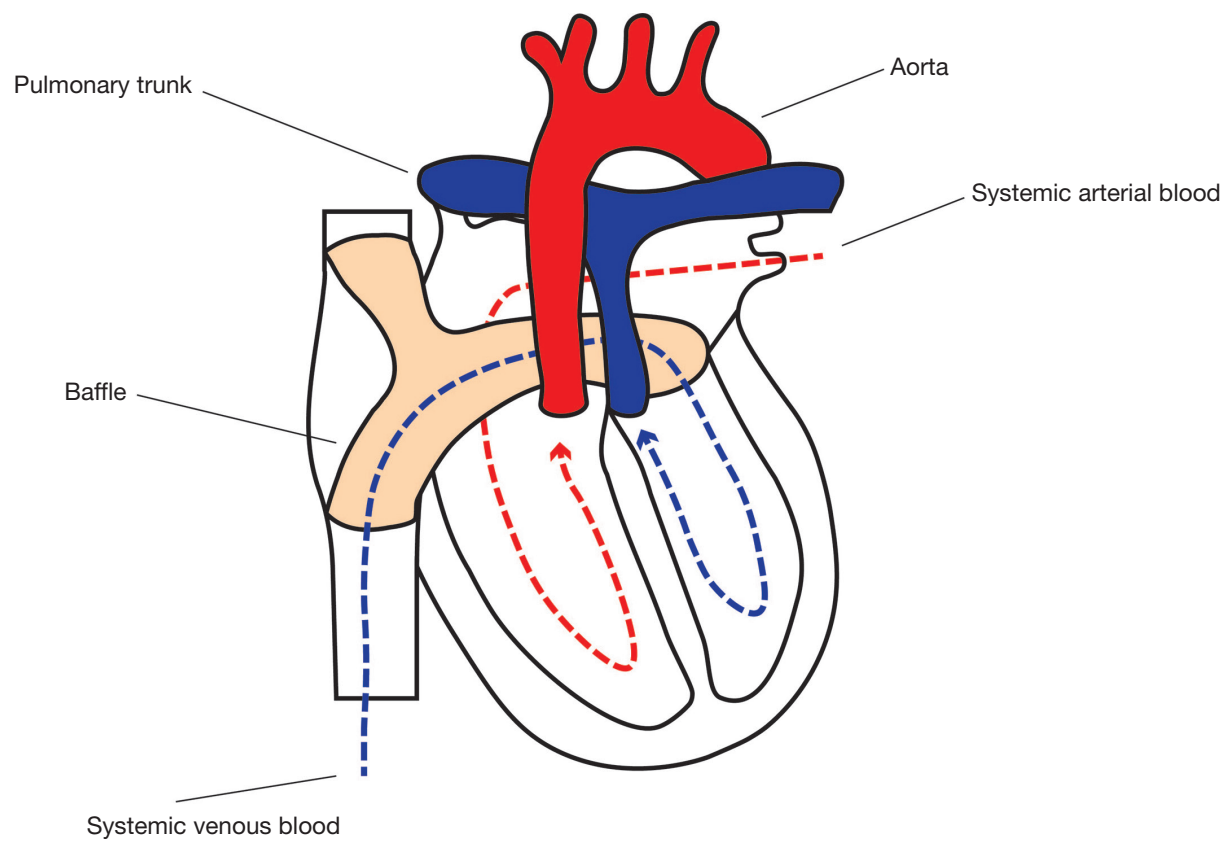

Figure 3 Anatomy after atrial switch operation (according to Mustard or Senning). The figure illustrates schematically the arterial and venous blood flow after arterial switch operation (Schema modified from (11) (https://www.sciencedirect.com/science/article/pii/ S1361841515001383?via\%3Dihub https://creativecommons.org/licenses/by/4.0/ and modified by Florian P. Reiter).

appropriate imaging techniques.

\section{Liver changes after Fontan-Operation for univentricular bearts}

After Fontan surgery [Figure 4 accordingly to (35)], liver changes are among the typical long-term consequences (36-39). Systolic and diastolic dysfunction of the heart, which regularly occur after Fontan surgery, as well as narrowing of the venous pathway or an increased pulmonary vascular resistance in a failing Fontan cause an increased central venous pressure and a passive liver congestion with ectasia of the liver sinusoids. Clinically this can lead to hepatomegaly, histologically to liver fibrosis or liver cirrhosis (36-43). Retrospective reviews of liver histopathology in patients with Fontan circulation consistently show near-universal fibrosis both early and late after Fontan completion. The extent of liver changes in patients with Fontan circulation is frequent and marked. In patients with a failing Fontan, the venous pressure, which burdens the liver, is constantly and continuously present. This is in contrast to patients with tricuspid valve regurgitation, where the venous pressure is pulsatile (17). On noninvasive imaging, $57 \%$ to $67 \%$ of patients with
Fontan physiology have ultrasound abnormalities of the liver, and $72 \%$ to $100 \%$ have abnormalities on CT or magnetic resonance (MR) imaging. This indicates Fontan physiology as a highly relevant risk factor for development of liver disease in the context of CHD $(36,44,45)$. Such liver alterations are usually more pronounced in adults than in children. Therefore, after cavopulmonary shunts, liver congestion is a major problem and seems to be present in many children with Fontan circulation $(46,47)$. In addition, hypoxemia of the liver parenchyma may occur in low cardiac output, which is typical for Fontan-hemodynamics, as well as by a right-left shunt (e.g., in fenestrated Fontan). If, as a consequence, the hepatocytes are damaged by this, liver dysfunction can also develop. It is important to note that after Fontan surgery, cases of hepatocellular carcinoma (HCC) at the bottom of liver cirrhosis have been described in the literature (8).

\section{Liver changes in CHD with severe pulmonary vascular disease (Eisenmenger-Syndrome)}

In the course of patients with severe pulmonary vascular disease and Eisenmenger's syndrome, hypoxic liver damage and/or reduced arterial liver perfusion may occur as well as 

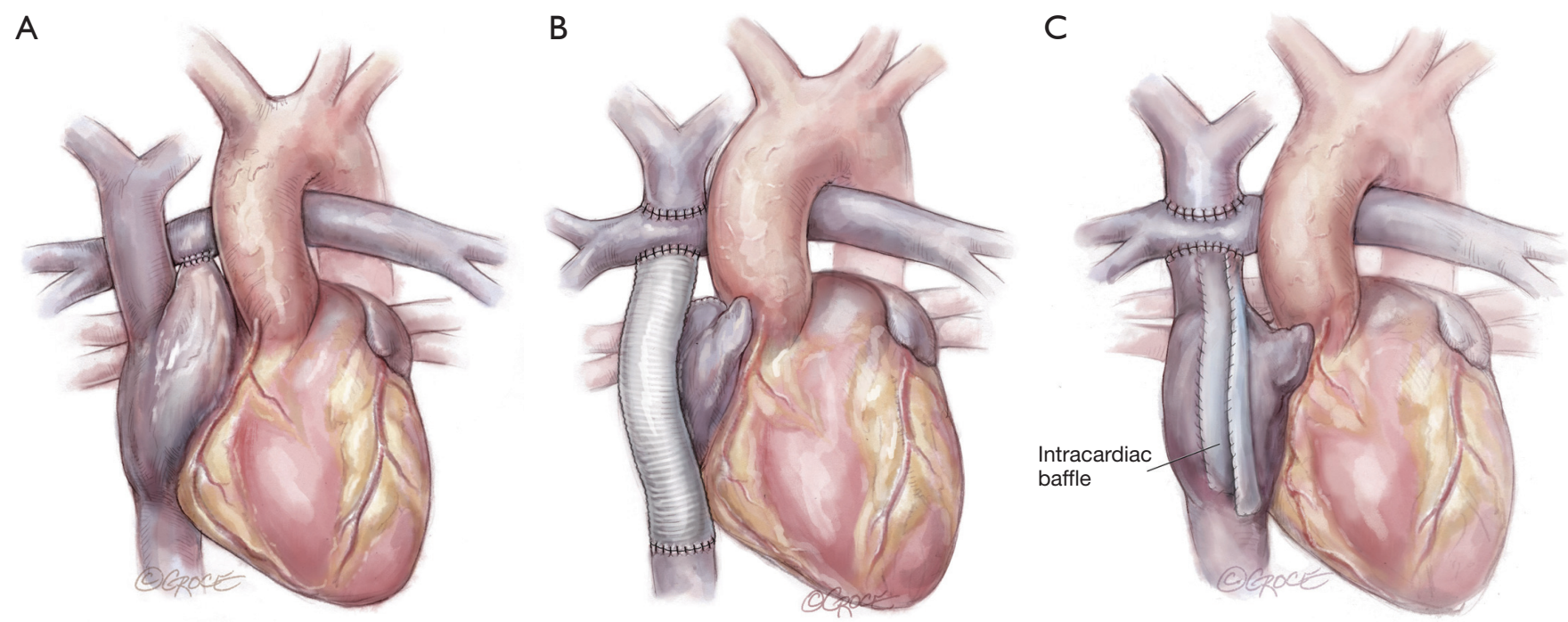

Figure 4 Schematic illustration of Fontan procedures. The figure illustrates schematically different Fontan procedures. (A) Atriopulmonary

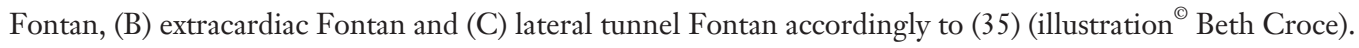

right heart failure with liver congestion due to progressive right heart failure. Right heart failure in combination with pulmonary hypertension causes a high risk for chronic liver congestion and can result in fibrosis or cirrhosis of the liver $(48,49)$. With decreasing cardiac output, reduced perfusion of the liver can cause ischemic hepatitis and hepatic coma (50).

\section{Management}

\section{Assessment of liver dysfunction in patients with CHD}

Biochemical liver tests should be assessed on a regular basis (every one to two years) in patients with CHD, who are at risk for the development of liver diseases (1). Abnormal biochemical liver tests are common in patients with CHD especially in patients' with Fontan circulation and with TGA after atrial switch $(1,51)$. Thoughtful interpretation may help to guide the differentiation of the underlying problem such as liver congestion, hepatic ischemia or ischemic cholangiopathy (17). Patients suffering from liver congestion typically present with mild to moderate altered liver values often showing isolated hyperbilirubinemia and elevated prothrombin time, while distinctive elevated transaminases typically occur in hepatic ischemia (17). A cholestatic profile with increased gamma-glutamyl transferase and alkaline phosphatase, may indicate ischemic cholangiopathy (17). However, we do not advise drawing conclusions only from assessing liver biochemistry, as abnormalities in liver biochemistry in patients with CHD can result out of a wide spectrum of causes, including side effects from concomitant medication. In case of abnormal liver biochemistry, a further hepatological assessment is strongly recommended. Thereby, an abdominal sonography (US) can provide important first aspects to differentiate causes of liver dysfunction in CHD. Typical signs of liver congestion are dilatation of the inferior caval vein and of the hepatic veins (52). Extrahepatic cholestasis as a cause of pathological liver biochemistry becomes obvious in case of bile duct dilatation in US. The evidence of splenomegaly should trigger an assessment of portal hypertension (53).

The use of elastography as non-invasive method to assess liver stiffness has greatly expanded the routine assessment of liver fibrosis. Thereby, a broad body of evidence validates its accuracy to identify liver cirrhosis in patients suffering from hepatitis C $(54,55)$. However, results in patients with CHD should be interpreted with caution as most evidence is available for its use in patients with chronic hepatitis and not in the context of hepatic congestion. Here liver stiffness may be overestimated due to hepatic afterload (56). Nevertheless, this may not lower its negative predictive value and its employment could help to rule out significant fibrosis. Contrast enhanced imaging should be employed in the assessment of adults with CHD and liver involvement. Invasive diagnostic procedures such as liver biopsy (of non-tumor tissue) or invasive measurement of hepatic venous pressure gradient should be restricted to individual situations and should be determined only after consultation 
between experienced hepatologists and congenital cardiologists, especially in the situation of anticoagulation or compromised hemostasis or hemodynamics.

\section{Management of portal hypertension and ascites in CHD}

Portal hypertension can lead to potentially life threating complications of liver cirrhosis such as variceal bleeding (57). Definitive diagnosis of portal hypertension requires an invasive measurement of the hepatic venous pressure gradient (HVPG) (18). Thereby portal hypertension is present with an HVPG $>5 \mathrm{mmHg}$ (18). As the invasive measurement of portal hypertension is a complex procedure, it is mostly diagnosed indirectly with presence of an enlarged spleen, ascites or portosystemic collaterals such as esophageal or gastric varices or occurrence of a Caput Medusae (18). Screening for esophageal and gastric varices is essential, as prophylactic medical and endoscopic approaches exist, that can reduce the risk of variceal bleeding. Varices are frequently found in patients with liver cirrhosis (about $43 \%$ in Child-Pugh class A and about $73 \%$ in Child-Pugh class $\mathrm{B} / \mathrm{C})(58)$. This resulted in the recommendation in the German guidelines that any patient with the first diagnosis of liver cirrhosis should undergo an esophagogastroscopy (EGD) for screening of varices (59). Depending on liver function these guidelines recommend an annual endoscopic surveillance in patients with Child-Pugh class B/C and every two years in patients with Child-Pugh class A (59). The more recent European guidelines recommend an EGD upon decompensation, while an annual endoscopic screening should be repeated if the etiological factor persists and/or the state of decompensation continues (60). Both guidelines strongly argue for a liberal EGD in case of liver cirrhosis as only thereby a management of varices can be initiated.

Here, the use of non-selective beta blockers (NSBB) can reduce the progression of varices before bleeding occurs (61). Endoscopic procedures such as variceal ligation (EVL) for varices of the esophagus (62) or prophylactic cyanoacrylate injection for gastric varices (63) were demonstrated having effects in bleeding prophylaxis. Thereby, either an endoscopic or medical (NSBB) treatment is recommended for primary prophylaxis in patients with varices (59). The exact management of varices would go beyond the scope of this review. However, we want to state here special aspects that need consideration in the management of portal hypertension in patients with liver disease due to CHD. First, some patients with CHD will receive an oral anticoagulation for embolic prophylaxis due to arrhythmias or suffer from coagulation disorders from their underlying CHD, e.g., patients with Eisenmenger syndrome. The periprocedural management of coagulation or anticoagulation before endoscopic procedures may be challenging in these patients and may favor the use of NSBB for prophylaxis of variceal bleeding, as both NSBB therapy and endoscopic prophylaxis do not differ in their effects on mortality in primary prophylaxis (64). However, from our perspective this should not avoid the routine employment of endoscopic surveillance as EGD is feasible under diagnostic intention without pausing anticoagulation. If a prophylactic medical or endoscopic approach will be taken, the choice will depend on individual aspects such as tolerability of NSBB and the development of varices under NSBB that may make an endoscopic approach necessary in case of treatment failure under NSBB. Furthermore, therapy with beta blockers may be indicated in CHD apart of varices due to cardiac indications. In our opinion, it might be of value in these situations that the use of NSBB would be weighed against the use of beta blockers as NSBB may have therapeutic effects apart from the cardiac indication on prophylaxis of variceal bleeding.

All these aspects may necessitate individual approaches that require interdisciplinary discussion between gastroenterologist and cardiologists.

The occurrence of ascites in patients suffering from CHD can result out of multiple reasons such as cardiac decompensation, protein losing enteropathy (1), or due to cardiac cirrhosis. An exact differentiation between cardiac or hepatic ascites can be difficult and may require the invasive measurement of hepatic venous pressure gradient to provide an exact differentiation (17). However, the management of ascites in patients with CHD may follow a more pragmatic approach. According to the German guidelines every new onset of ascites or any deterioration of ascites or any new complications from liver cirrhosis should result in a diagnostic paracentesis to rule out the evidence of spontaneous bacterial peritonitis (SBP) (65). From a pragmatic point of view this can also be recommended in patients who develop ascites in the context of CHD, as the beginning of liver dysfunction is difficult to define by non-invasive measurements in patients with CHD and liver dysfunction should always be suspected in the case of new onset or deterioration of ascites in patients with CHD. Furthermore, the determination of the serumascitic-albumin-gradient (SAAG) and of the total protein in ascitic fluid can be helpful to differentiate hepatic from cardiac ascites (17). Here a SAAG $>1.1 \mathrm{~g} / \mathrm{dL}$ indicates that 
portal hypertension is the cause for ascites development, while values $<1.1 \mathrm{~g} / \mathrm{dL}$ suggest different causes for ascites such as malignancy, tuberculosis or pancreatitis (66). However, both ascites related to cardiac as well as to hepatic decompensation show a SAAG $>1.1 \mathrm{~g} / \mathrm{dL}$ (66). Here the ascitic protein concentration can help to differentiate between cardiac or hepatic origin. While ascites related to cardiac decompensation usually shows a protein concentration $>2.5 \mathrm{~g} / \mathrm{dL}$, ascites related to cirrhosis shows protein levels $<2.5 \mathrm{~g} / \mathrm{dL}$.

The fact that liver disease associated coagulopathy is not a contraindication against paracentesis unless platelet counts fall below 20,000/ $\mathrm{LL}$ or Quick values fall below $<20 \%$ makes paracentesis practicable in a liberal fashion also in patients with CHD associated liver disease (65). To our best knowledge, no clear recommendations on the management of anticoagulation before paracentesis exist, a situation that may be of importance in patients with CHD, as permanent prophylaxis of thromboembolic events from arrhythmias using oral anticoagulants is a common scenario in these patients. One study in patients with Budd-Chiari syndrome, who are generally treated with oral anticoagulants, and might resemble patients with CHD, did not show evidence of hemoperitoneum or bleeding in 51 performed paracenteses without pausing anticoagulation (67). This may indicate that paracentesis could be of relatively low bleeding risk even under oral anticoagulation.

Symptomatic diuretic management of ascites typically comprises an anti-mineralocorticoid drug (spironolactone) with an escalation on an combination with a loop diuretic as far as ascites is not manageable with only antimineralocorticoid therapy (60). Both substance categories are frequently used in the treatment of cardiac decompensation potentially justifying their use for both cardiac and hepatic ascites from pragmatic perspectives. For refractory cases the use of a thiazide diuretic can be considered (66).

Polymorphonuclear (PMN) cells should be assessed in ascites after paracentesis and SBP should be considered when more than $250 \mathrm{PMN}$ cells per $\mathrm{mm}^{3}$ ascites are evident. For the diagnostic and therapeutic work-up in the case of SBP we refer on the current American, European and German guidelines $(60,65,68)$.

The use of a Transjugular portosystemic shunt for the treatment of portal hypertension and ascites is limited in patients with CHD as an increase of right-sided pressure may be present more frequently in patients with CHD and could interfere with shunt function (17). Furthermore, the increase of preload may harm cardiac function (17).

\section{Surveillance of HCC in CHD}

HCC is a major cause for cancer related mortality (69). The majority of HCCs arise in the context of chronic liver diseases and liver cirrhosis. HCC is the leading cause of death in patients with liver cirrhosis (70-72). Unfortunately, occurrence of HCC is also prevalent in patients suffering from CHD, particularly in patients with Fontan circulation $(8,73)$ with an annual incidence of $1.5 \%$ to $5 \%$ in cirrhosis (8). In the general population HCC is typically diagnosed at advanced stages (74), when local curative therapies are not feasible anymore. Despite great advances in the treatment of advanced HCC with several new treatment options that became available over the last few years in first as well as in second line treatment, such as regorafenib (75), lenvatinib (76), cabozantinib (77), ramucirumab (78) or the combination of atezolizumab and bevacizumab (79), prognosis remains poor. Thereby, a strict surveillance of potential treatable patients susceptible for development of HCCs is essential. A situation that is generally the case in patients with CHD associated liver disease. Several international guidelines recommend HCC surveillance every six month by US in patients with liver cirrhosis $(80,81)$. The European guidelines recommend US as surveillance modality for HCC with an acceptable diagnostic accuracy $(80,82,83)$. If the surveillance should be performed together with a measurement of alphafetoprotein or not is controversial $(80,81)$. The screening of HCC in patients suffering from liver congestion due to Budd Chiari Syndrome or CHD can be challenging due to the development of hypervascular nodules under liver congestion $(17,84,85)$. These nodules, that are typically defined as intense vascular blushes observed during arterial phase imaging (17), may correspond to focal nodular hyperplasia (42). These nodules may hamper surveillance and the application of other contrast enhanced imaging modalities may become necessary. However, magnetic resonance imagining is often restricted due to the high frequency of non-MRI-compatible pace-makers in patients with CHD. Computed tomography imaging on a regular basis could result in a significant exposure to ionizing radiation over the course of a patient's lifetime, especially when some authors recommend the start of HCC surveillance, e.g., at 5 years after Fontan completion (1). Contrast enhanced US may be a suitable, no-radiation technique to augment diagnostic accuracy in the assessment of nodules in patients suffering from cardiac cirrhosis and CHD (86). In summary, the surveillance of HCC can be challenging in patients with $\mathrm{CHD}$ and the described aspects 
should find consideration.

\section{Liver transplantation in patients with CHD}

Liver transplantation (LiTx) is the therapy of choice for the treatment of advanced liver cirrhosis. However, there are studies indicating that $\mathrm{CHD}$ related liver disease or even liver cirrhosis can improve after restoration of liver congestion achieved by successful heart transplantation (HTx) $(87,88)$. These encouraging results are overshaded by the fact that liver dysfunction reflects a relevant risk factor for morbidity and mortality in cardiac surgery or HTx (89-91). Combined HTx/LiTx has been reported as a successful treatment option in children with univentricular hearts (92) and may be an option in selected cases of CHD-associated liver disease. The consideration of these aspects results in a conflicting situation where the hope of an improvement of liver dysfunction after HTx is counterbalanced by relevant morbidity and mortality related to liver dysfunction if only HTx is performed. Unfortunately, large trials that guide the decision making for isolated HTx or LiTx or combined $\mathrm{HTx}_{\mathrm{x}} / \mathrm{LiTx}$ are lacking and current decisions have to be made for individual situations by a multidisciplinary board of experts. Whether or not the MELD score can help to guide decision making for or against LiTx is debated (17) and further studies are warranted to clarify the value of the MELD score in these certain situations. However, from our point LiTx, potentially in combination with HTx, in the context of CHD should be discussed in the presence of HCC lesions inside the "Milan criteria" (93) or inside the "up to seven criteria" (94) or if a relevant hepatic dysfunction reflected by a MELD score of $\geq 15$ points is present (95). It has to be emphasized that sole LiTx is only possible, when a sufficient cardiac function is preserved.

Although indications for heart transplantation shall not be part of this review, we want to highlight here that the prognosis of CHD without HTx has to be considered before initiating an evaluation for isolated LiTx as perioperative cardiac decompensation may occur, heart disease may progress and persistent liver congestion could result in recurrence of liver dysfunction after LiTx.

\section{Conclusions}

Here we summarize pathophysiological aspects of liver dysfunction related to CHD such as backward/forward failure, hypoxemia, and ischemia and try to provide an understanding of hemodynamic alterations in patients with
CHD in the context of the unique blood supply of the liver. Furthermore, this overview lists perspectives in the context of particular CHDs that are frequently associated with development of liver dysfunction. We also draw attention to frequent causes of liver dysfunction that occur independently of hemodynamic alterations in patients with CHD such as NAFLD and viral hepatitis. Important aspects in medical care are listed to guide pediatric cardiologist and hepatologists in the treatment of patients with CHD.

Fortunately, great achievement in therapy of patients with CHD has been reached over the time and survival accounts for several decades nowadays. Modern care of patients with CHD should also comprise non-cardiac problems such as liver diseases associated with CHD that have become more apparent in the context of improved survival of this population. The optimal therapy necessitates a close multidisciplinary care and certain aspects related to CHD should be considered in the treatment of these patients. Currently we face low evidence for decision making in these vulnerable population and most therapeutic decisions are based on expert opinion, that should be made in a multidisciplinary setting. We strongly encourage the scientific community to perform further prospective studies to gain evidence to optimize the treatment of hepatic dysfunction in this patient population.

\section{Acknowledgments}

Funding: None.

\section{Footnote}

Reporting Checklist: The authors have completed the SURGE reporting checklist. Available at http://dx.doi.org/ cdt-20-595

Provenance and Peer Review: This article was commissioned by the editorial office, Cardiovascular Diagnosis and Therapy for the series "Current Management Aspects in Adult Congenital Heart Disease (ACHD): Part III". The article has undergone external peer review.

Conflicts of Interest: All authors have completed the ICMJE uniform disclosure form (available at http://dx.doi.org/ cdt-20-595). The series "Current Management Aspects in Adult Congenital Heart Disease (ACHD): Part III" was commissioned by the editorial office without any funding or sponsorship. HK served as the unpaid Guest 
Editor of the series and serves as an unpaid editorial board member of Cardiovascular Diagnosis and Therapy from Feb 2018 to Jan 2020. Dr. GD reports personal fees and nonfinancial support from AbbVie, personal fees from Falk Foundation, personal fees and non-financial support from Gilead, personal fees from GMP Orphan, personal fees and non-financial support from Intercept, personal fees from Novartis, outside the submitted work. The authors have no other conflicts of interest to declare.

Ethical Statement: The authors are accountable for all aspects of the work in ensuring that questions related to the accuracy or integrity of any part of the work are appropriately investigated and resolved.

Open Access Statement: This is an Open Access article distributed in accordance with the Creative Commons Attribution-NonCommercial-NoDerivs 4.0 International License (CC BY-NC-ND 4.0), which permits the noncommercial replication and distribution of the article with the strict proviso that no changes or edits are made and the original work is properly cited (including links to both the formal publication through the relevant DOI and the license). See: https://creativecommons.org/licenses/by-nc-nd/4.0/.

\section{References}

1. Lui GK, Saidi A, Bhatt AB, et al. Diagnosis and Management of Noncardiac Complications in Adults With Congenital Heart Disease: A Scientific Statement From the American Heart Association. Circulation 2017;136:e348-92.

2. Khairy P, Ionescu-Ittu R, Mackie AS, et al. Changing mortality in congenital heart disease. J Am Coll Cardiol 2010;56:1149-57.

3. Warnes CA, Liberthson R, Danielson GK, et al. Task force 1: the changing profile of congenital heart disease in adult life. J Am Coll Cardiol 2001;37:1170-5.

4. Warnes CA, Williams RG, Bashore TM, et al. ACC/ AHA 2008 guidelines for the management of adults with congenital heart disease: a report of the American College of Cardiology/American Heart Association Task Force on Practice Guidelines (Writing Committee to Develop Guidelines on the Management of Adults With Congenital Heart Disease). Developed in Collaboration With the American Society of Echocardiography, Heart Rhythm Society, International Society for Adult Congenital Heart Disease, Society for Cardiovascular Angiography and
Interventions, and Society of Thoracic Surgeons. J Am Coll Cardiol 2008;52:e143-e263.

5. Neidenbach RC, Lummert E, Vigl M, et al. Non-cardiac comorbidities in adults with inherited and congenital heart disease: report from a single center experience of more than 800 consecutive patients. Cardiovasc Diagn Ther 2018;8:423-31.

6. Singh S, Desai R, Fong HK, et al. Extra-cardiac comorbidities or complications in adults with congenital heart disease: a nationwide inpatient experience in the United States. Cardiovasc Diagn Ther 2018;8:814-9.

7. Engelings CC, Helm PC, Abdul-Khaliq H, et al. Cause of death in adults with congenital heart disease - An analysis of the German National Register for Congenital Heart Defects. Int J Cardiol 2016;211:31-6.

8. Asrani SK, Warnes CA, Kamath PS. Hepatocellular carcinoma after the Fontan procedure. N Engl J Med 2013;368:1756-7.

9. Correale M, Tarantino N, Petrucci R, et al. Liver disease and heart failure: Back and forth. Eur J Intern Med 2018;48:25-34.

10. Alonso-Gonzalez R. Liver dysfunction and congenital heart disease: Are we ready for the epidemic? Int J Cardiol 2017;249:169-70.

11. Zuluaga MA, Burgos N, Mendelson AF, et al. Voxelwise atlas rating for computer assisted diagnosis: Application to congenital heart diseases of the great arteries. Med Image Anal 2015;26:185-94.

12. Weisberg IS, Jacobson IM. Cardiovascular diseases and the liver. Clin Liver Dis 2011;15:1-20.

13. Myers RP, Cerini R, Sayegh R, et al. Cardiac hepatopathy: clinical, hemodynamic, and histologic characteristics and correlations. Hepatology 2003;37:393-400.

14. Hidaka H, Iwakiri Y. Hepatic congestion leads to fibrosis: findings in a newly developed murine model. Hepatology 2015;61:428-30.

15. Giallourakis CC, Rosenberg PM, Friedman LS. The liver in heart failure. Clin Liver Dis 2002;6:947-67, viii-ix.

16. Cohen SB, Ginde S, Bartz PJ, et al. Extracardiac complications in adults with congenital heart disease. Congenit Heart Dis 2013;8:370-80.

17. Asrani SK, Asrani NS, Freese DK, et al. Congenital heart disease and the liver. Hepatology 2012;56:1160-9.

18. Bloom S, Kemp W, Lubel J. Portal hypertension: pathophysiology, diagnosis and management. Intern Med J 2015;45:16-26.

19. Nagdyman N, Mebus S, Kugel J, et al. Non-invasive assessment of liver alterations in Senning and Mustard 
patients. Cardiovasc Diagn Ther 2019;9:S198-S208.

20. Afilalo J, Therrien J, Pilote L, et al. Geriatric congenital heart disease: burden of disease and predictors of mortality. J Am Coll Cardiol 2011;58:1509-15.

21. Marelli AJ, Mackie AS, Ionescu-Ittu R, et al. Congenital heart disease in the general population: changing prevalence and age distribution. Circulation 2007;115:163-72.

22. Wang A, Book WM, McConnell M, et al. Prevalence of hepatitis $\mathrm{C}$ infection in adult patients who underwent congenital heart surgery prior to screening in 1992. Am J Cardiol 2007;100:1307-9.

23. Cox DA, Ginde S, Tweddell JS, et al. Outcomes of a hepatitis $\mathrm{C}$ screening protocol in at-risk adults with prior cardiac surgery. World J Pediatr Congenit Heart Surg 2014;5:503-6.

24. Younossi ZM, Koenig AB, Abdelatif D, et al. Global epidemiology of nonalcoholic fatty liver disease-Metaanalytic assessment of prevalence, incidence, and outcomes. Hepatology 2016;64:73-84.

25. Zhang Z, Wang P, Guo F, et al. Chronic heart failure in patients with nonalcoholic fatty liver disease: prevalence, clinical features, and relevance. J Int Med Res 2018;46:3959-69.

26. Cobanoglu A, Abbruzzese PA, Freimanis I, et al. Pericardial baffle complications following the Mustard operation. Age-related incidence and ease of management. J Thorac Cardiovasc Surg 1984;87:371-8.

27. Graham TP, Jr. Hemodynamic residua and sequelae following intraatrial repair of transposition of the great arteries: a review. Pediatr Cardiol 1982;2:203-13.

28. Hurwitz RA, Papanicolaou N, Treves S, et al. Radionuclide angiocardiography in evaluation of patients after repair of transposition of the great arteries. Am J Cardiol 1982;49:761-5.

29. Theissen $P$, Kaemmerer H, Sechtem U, et al. Magnetic resonance imaging of cardiac function and morphology in patients with transposition of the great arteries following Mustard procedure. Thorac Cardiovasc Surg 1991;39 Suppl 3:221-4.

30. Kron IL, Rheuban KS, Joob AW, et al. Baffle obstruction following the Mustard operation: cause and treatment. Ann Thorac Surg 1985;39:112-5.

31. Arciniegas E, Farooki ZQ, Hakimi M, et al. Results of the Mustard operation for dextro-transposition of the great arteries. J Thorac Cardiovasc Surg 1981;81:580-7.

32. Penkoske PA, Westerman GR, Marx GR, et al. Transposition of the great arteries and ventricular septal defect: results with the Senning operation and closure of the ventricular septal defect in infants. Ann Thorac Surg 1983;36:281-8.

33. Venables AW, Edis B, Clarke CP. Vena caval obstruction complicating the Mustard operation for complete transposition of the great arteries. Eur J Cardiol 1974;1:401-10.

34. Williams WG, Trusler GA, Kirklin JW, et al. Early and late results of a protocol for simple transposition leading to an atrial switch (Mustard) repair. J Thorac Cardiovasc Surg 1988;95:717-26.

35. Jaquiss RDB, Woods RK. Insertion of the total artificial heart in the Fontan circulation. Ann Cardiothorac Surg 2020;9:134-40.

36. Camposilvan S, Milanesi O, Stellin G, et al. Liver and cardiac function in the long term after Fontan operation. Ann Thorac Surg 2008;86:177-82.

37. Friedrich-Rust M, Koch C, Rentzsch A, et al. Noninvasive assessment of liver fibrosis in patients with Fontan circulation using transient elastography and biochemical fibrosis markers. J Thorac Cardiovasc Surg 2008;135:560-7.

38. Kiesewetter CH, Sheron N, Vettukattill JJ, et al. Hepatic changes in the failing Fontan circulation. Heart 2007;93:579-84.

39. van Nieuwenhuizen RC, Peters M, Lubbers LJ, et al. Abnormalities in liver function and coagulation profile following the Fontan procedure. Heart 1999;82:40-6.

40. Allan CK. Intensive care of the adult patient with congenital heart disease. Prog Cardiovasc Dis 2011;53:274-80.

41. Alvarez AM, Mukherjee D. Liver abnormalities in cardiac diseases and heart failure. Int J Angiol 2011;20:135-42.

42. Ghaferi AA, Hutchins GM. Progression of liver pathology in patients undergoing the Fontan procedure: Chronic passive congestion, cardiac cirrhosis, hepatic adenoma, and hepatocellular carcinoma. J Thorac Cardiovasc Surg 2005;129:1348-52.

43. Sherlock $\mathrm{S}$. The liver in heart failure; relation of anatomical, functional, and circulatory changes. Br Heart J 1951;13:273-93.

44. Sugimoto M, Oka H, Kajihama A, et al. Non-invasive assessment of liver fibrosis by magnetic resonance elastography in patients with congenital heart disease undergoing the Fontan procedure and intracardiac repair. J Cardiol 2016;68:202-8.

45. Goldberg DJ, Surrey LF, Glatz AC, et al. Hepatic Fibrosis Is Universal Following Fontan Operation, and Severity is Associated With Time From Surgery: A Liver Biopsy and Hemodynamic Study. J Am Heart Assoc 2017;6. 
46. Hebson CL, McCabe NM, Elder RW, et al. Hemodynamic phenotype of the failing Fontan in an adult population. Am J Cardiol 2013;112:1943-7.

47. Rathgeber SL, Guttman OR, Lee AF, et al. FontanAssociated Liver Disease: Spectrum of Disease in Children and Adolescents. J Am Heart Assoc 2020;9:e012529.

48. Mebus S, Nagdyman N, Kugel J, et al. Non-invasive assessment of liver changes in Eisenmenger patients. Int J Cardiol 2017;249:140-4.

49. Takeda Y, Takeda Y, Tomimoto S, et al. Bilirubin as a prognostic marker in patients with pulmonary arterial hypertension. BMC Pulm Med 2010;10:22.

50. Naschitz JE, Slobodin G, Lewis RJ, et al. Heart diseases affecting the liver and liver diseases affecting the heart. Am Heart J 2000;140:111-20.

51. Wu FM, Ukomadu C, Odze RD, et al. Liver disease in the patient with Fontan circulation. Congenit Heart Dis 2011;6:190-201.

52. Wells ML, Fenstad ER, Poterucha JT, et al. Imaging Findings of Congestive Hepatopathy. Radiographics 2016;36:1024-37.

53. Bolognesi M, Merkel C, Sacerdoti D, et al. Role of spleen enlargement in cirrhosis with portal hypertension. Dig Liver Dis 2002;34:144-50.

54. Castera L, Vergniol J, Foucher J, et al. Prospective comparison of transient elastography, Fibrotest, APRI, and liver biopsy for the assessment of fibrosis in chronic hepatitis C. Gastroenterology 2005;128:343-50.

55. Stebbing J, Farouk L, Panos G, et al. A meta-analysis of transient elastography for the detection of hepatic fibrosis. J Clin Gastroenterol 2010;44:214-9.

56. Kutty SS, Peng Q, Danford DA, et al. Increased hepatic stiffness as consequence of high hepatic afterload in the Fontan circulation: a vascular Doppler and elastography study. Hepatology 2014;59:251-60.

57. Wright AS, Rikkers LF. Current management of portal hypertension. J Gastrointest Surg 2005;9:992-1005.

58. Kovalak M, Lake J, Mattek N, et al. Endoscopic screening for varices in cirrhotic patients: data from a national endoscopic database. Gastrointest Endosc 2007;65:82-8.

59. Denzer U, Beilenhoff U, Eickhoff A, et al. S2k guideline: quality requirements for gastrointestinal endoscopy, AWMF registry no. 021-022. Z Gastroenterol 2015;53:E1-227.

60. European Association for the Study of the Liver. Electronic address eee, European Association for the Study of the L. EASL Clinical Practice Guidelines for the management of patients with decompensated cirrhosis. J
Hepatol 2018;69:406-60.

61. Merkel C, Marin R, Angeli P, et al. A placebo-controlled clinical trial of nadolol in the prophylaxis of growth of small esophageal varices in cirrhosis. Gastroenterology 2004;127:476-84.

62. Imperiale TF, Chalasani N. A meta-analysis of endoscopic variceal ligation for primary prophylaxis of esophageal variceal bleeding. Hepatology 2001;33:802-7.

63. Mishra SR, Sharma BC, Kumar A, et al. Primary prophylaxis of gastric variceal bleeding comparing cyanoacrylate injection and beta-blockers: a randomized controlled trial. J Hepatol 2011;54:1161-7.

64. Gluud LL, Krag A. Banding ligation versus beta-blockers for primary prevention in oesophageal varices in adults. Cochrane Database Syst Rev 2012:CD004544.

65. Gerbes AL, Gulberg V, Sauerbruch T, et al. German S 3 -guideline "ascites, spontaneous bacterial peritonitis, hepatorenal syndrome". Z Gastroenterol 2011;49:749-79.

66. Gerbes AL, Labenz J, Appenrodt B, et al. [Updated S2kGuideline "Complications of liver cirrhosis". German Society of Gastroenterology (DGVS)]. Z Gastroenterol 2019;57:611-80.

67. Devarbhavi H, Murali AR. Safety of Ascitic Paracentesis in Patients with Budd-Chiari Syndrome on Oral Anticoagulation and Elevated International Normalized Ratio. J Clin Exp Hepatol 2015;5:310-3.

68. Runyon BA, Aasld. Introduction to the revised American Association for the Study of Liver Diseases Practice Guideline management of adult patients with ascites due to cirrhosis 2012. Hepatology 2013;57:1651-3.

69. Llovet JM, Zucman-Rossi J, Pikarsky E, et al. Hepatocellular carcinoma. Nat Rev Dis Primers 2016;2:16018.

70. Schuppan D, Afdhal NH. Liver cirrhosis. Lancet 2008;371:838-51.

71. Williams R. Global challenges in liver disease. Hepatology 2006;44:521-6.

72. De Toni EN, Schlesinger-Raab A, Fuchs M, et al. Age independent survival benefit for patients with hepatocellular carcinoma (HCC) without metastases at diagnosis: a population-based study. Gut 2020;69:168-76.

73. McCabe N, Farris AB, Hon H, et al. Hepatocellular carcinoma in an adult with repaired tetralogy of fallot. Congenit Heart Dis 2013;8:E139-44.

74. Llovet JM, Burroughs A, Bruix J. Hepatocellular carcinoma. Lancet 2003;362:1907-17.

75. Bruix J, Qin S, Merle P, et al. Regorafenib for patients with hepatocellular carcinoma who progressed on sorafenib 
treatment (RESORCE): a randomised, double-blind, placebo-controlled, phase 3 trial. Lancet 2017;389:56-66.

76. Kudo M, Finn RS, Qin S, et al. Lenvatinib versus sorafenib in first-line treatment of patients with unresectable hepatocellular carcinoma: a randomised phase 3 noninferiority trial. Lancet 2018;391:1163-73.

77. Abou-Alfa GK, Meyer T, Cheng AL, et al. Cabozantinib in Patients with Advanced and Progressing Hepatocellular Carcinoma. N Engl J Med 2018;379:54-63.

78. Zhu AX, Park JO, Ryoo BY, et al. Ramucirumab versus placebo as second-line treatment in patients with advanced hepatocellular carcinoma following first-line therapy with sorafenib (REACH): a randomised, double-blind, multicentre, phase 3 trial. Lancet Oncol 2015;16:859-70.

79. Finn RS, Qin S, Ikeda M, et al. Atezolizumab plus Bevacizumab in Unresectable Hepatocellular Carcinoma. N Engl J Med 2020;382:1894-905.

80. European Association for the Study of the Liver. Electronic address eee, European Association for the Study of the L. EASL Clinical Practice Guidelines: Management of hepatocellular carcinoma. J Hepatol 2018;69:182-236.

81. Heimbach JK, Kulik LM, Finn RS, et al. AASLD guidelines for the treatment of hepatocellular carcinoma. Hepatology 2018;67:358-80.

82. Bolondi L. Screening for hepatocellular carcinoma in cirrhosis. J Hepatol 2003;39:1076-84.

83. Singal A, Volk ML, Waljee A, et al. Meta-analysis: surveillance with ultrasound for early-stage hepatocellular carcinoma in patients with cirrhosis. Aliment Pharmacol Ther 2009;30:37-47.

84. Ford RM, Book W, Spivey JR. Liver disease related to the heart. Transplant Rev (Orlando) 2015;29:33-7.

85. Tellez L, Rodriguez-Santiago E, Albillos A. FontanAssociated Liver Disease: A Review. Ann Hepatol 2018;17:192-204.

Cite this article as: Reiter FP, Hadjamu NJ, Nagdyman N, Zachoval R, Mayerle J, De Toni EN, Kaemmerer H, Denk G. Congenital heart disease-associated liver disease: a narrative review. Cardiovasc Diagn Ther 2021;11(2):577-590. doi: 10.21037/cdt-20-595
86. Strobel D, Seitz K, Blank W, et al. Contrast-enhanced ultrasound for the characterization of focal liver lesions-diagnostic accuracy in clinical practice (DEGUM multicenter trial). Ultraschall Med 2008;29:499-505.

87. Dichtl W, Vogel W, Dunst KM, et al. Cardiac hepatopathy before and after heart transplantation. Transpl Int 2005;18:697-702.

88. Crespo-Leiro MG, Robles O, Paniagua MJ, et al. Reversal of cardiac cirrhosis following orthotopic heart transplantation. Am J Transplant 2008;8:1336-9.

89. Bizouarn P, Ausseur A, Desseigne P, et al. Early and late outcome after elective cardiac surgery in patients with cirrhosis. Ann Thorac Surg 1999;67:1334-8.

90. Hayashida N, Shoujima T, Teshima H, et al. Clinical outcome after cardiac operations in patients with cirrhosis. Ann Thorac Surg 2004;77:500-5.

91. Hsu RB, Chang CI, Lin FY, et al. Heart transplantation in patients with liver cirrhosis. Eur J Cardiothorac Surg 2008;34:307-12.

92. Hollander SA, Reinhartz O, Maeda K, et al. Intermediateterm outcomes after combined heart-liver transplantation in children with a univentricular heart. J Heart Lung Transplant 2013;32:368-70.

93. Mazzaferro V, Regalia E, Doci R, et al. Liver transplantation for the treatment of small hepatocellular carcinomas in patients with cirrhosis. $\mathrm{N}$ Engl J Med 1996;334:693-9.

94. Mazzaferro V, Llovet JM, Miceli R, et al. Predicting survival after liver transplantation in patients with hepatocellular carcinoma beyond the Milan criteria: a retrospective, exploratory analysis. Lancet Oncol 2009;10:35-43.

95. Freeman RB. MELD: the holy grail of organ allocation? J Hepatol 2005;42:16-20. 